\title{
Kinetic Analysis for Non-isothermal Decomposition of Unirradiated and $\gamma$-Irradiated Indium Acetyl Acetonate
}

\author{
Refaat Mohammed Mahfouz*, Sharifa Al-Ahmari, Amaal Al-Fawaz, Zaid Al-Othman, \\ Ismail Khaleel Warad, Mohammed Rafiq Hussain Siddiqui \\ Department of chemistry, College of Science, King Saud University, \\ Riyadh 11451, P.O. Box 2455, Kingdom of Saudi Arabia
}

Received: April 12, 2010

\begin{abstract}
Kinetic studies for the non-isothermal decomposition of un-irradiated and $\gamma$-irradiated indium acetyl acetonate $\operatorname{In}(\mathrm{acac})_{3}$ with $10^{2} \mathrm{kGy}$ total $\gamma$-ray dose were carried out in static air. The results showed that the decomposition proceeds in one major step in the temperature range of $150-250{ }^{\circ} \mathrm{C}$ with the formation of $\mathrm{In}_{2} \mathrm{O}_{3}$ as solid residue. The non-isothermal data for un-irradiated and $\gamma$-irradiated $\operatorname{In}(\mathrm{acac})_{3}$ were analysed using linear Flynn-WallOzawa (FWO) and nonlinear Vyazovkin (VYZ) iso-conversional methods. The results of application of these free models on the investigated data showed a systematic dependence of $\mathrm{E}_{\mathrm{a}}$ on $\alpha$ indicating a simple decomposition process. No significant changes were observed in both decomposition behaviour and (E $\alpha-\alpha)$ dependency between unirradiated and $\gamma$-irradiated $\operatorname{In}(\mathrm{acac})_{3}$. Calcination of $\operatorname{In}(\mathrm{acac})_{3}$ at $400{ }^{\circ} \mathrm{C}$ for 5 hours led to the formation of $\operatorname{In}_{2} \mathrm{O}_{3}$ monodispersed nanoparticles. X-ray diffraction, FTIR and SEM techniques were employed for characterization of the synthesised nanoparticles. This is the first attempt to prepare $\operatorname{In}_{2} \mathrm{O}_{3}$ nanoparticles by solid state thermal decomposition of $\operatorname{In}(\mathrm{acac})_{3}$.
\end{abstract}

Keywords: thermal decomposition, gamma irradiation, nanoparticles

\section{Introduction}

Thermal treatment of inorganic substances has a great synthetic potential as it may turn simple compounds into advanced materials, such as ceramics, catalysts, and glasses and could reproducibly lead in most cases to metal or metal oxide nanoparticles displaying a very narrow size distribution ${ }^{1,2}$. Many recent studies on the thermal decomposition of inorganic solids have include measurements on samples that were exposed to radiation prior to heating with the aim to investigate the effect of ionizing radiation on the kinetics and thermal decomposition behaviour of inorganic compounds ${ }^{3,4}$. Indium acetylacetonate is a suitable metal-organic compound for preparation of $\operatorname{In}_{2} \mathrm{O}_{3}$ which has many applications in optoelectronics device such as solar cells and liquid crystal display ${ }^{5}$. Moreover it is an important material in the gas sensor fields. No previous studies are available up to now on the thermal decomposition kinetics of both un-irradiated and $\gamma$-irradiated $\operatorname{In}(\mathrm{acac})_{3}{ }^{[6,7]}$.

In the present work, the thermal decomposition behaviour of un-irradiated and $\gamma$-irradiated $\operatorname{In}(\mathrm{acac})_{3}$ was investigated in air with the aim to: a) examine the kinetics of non-isothermal decomposition of both un-irradiated and $\gamma$-irradiated $\operatorname{In}(\mathrm{acac})_{3}$ using model free isoconversional approach; b) clarify the effects of $\gamma$-irradiation on the thermal decomposition behaviour; and c) finally to follow the chemical composition of the solid residues obtained at different temperature and attempting to prepare $\operatorname{In}_{2} \mathrm{O}_{3}$ at nanoscale by thermal decomposition of indium acetylacetonate.

\section{Experimental}

Indium acetylacetonate was obtained commercially from Aldrich $L t d$ and used without further purification. Samples were dried in a desiccator before analysis. For thermal experiments a thermogravimetric analyzer was used (TGA-7, Perkin Elmer ${ }^{\circledR}$ ). The amount of the sample was kept at $10 \pm 0.1 \mathrm{mg}$. Under dynamic (nonisothermal conditions) four linear heating rates $\left(5,10,15,20^{\circ} \mathrm{C} / \mathrm{min}\right)$ were applied. For irradiation, sample were encapsulated under vacuum in glass vials and exposed to successively increasing doses of radiation at constant intensity using a Co-60 $\gamma$-ray cell 220 (Nordion INT-INC, Ontario, Canada) at a dose rate of $10^{4} \mathrm{~Gy} / \mathrm{h}$.

The fraction decomposed or the extent of conversion, $\alpha$ was calculated as (Equation 1)

$$
\alpha=\frac{M_{0}-M}{M-M_{f}}
$$

where $M_{o}, M, M_{f}$ are the initial, actual and final sample masses respectively. The infrared spectra were recorded as a $\mathrm{KBr}$ pellets using a Perkin Elmer 1000 FT-IR spectrophotometer, XRD was carried out on a Siemens D 5000 X-ray diffractometer $(\mathrm{Cu} \mathrm{K \alpha}, \lambda=1.5418 \AA$ ).

Theory: a single step process for solid state decomposition has the following kinetics equation (Equation 2)

$$
\frac{d \alpha}{d t}=k(t) f(\alpha)
$$

where $\alpha$ is the extent of conversation, $\mathrm{K}(\mathrm{T})$ is a temperature dependent reaction rate constant and $\mathrm{f}(\alpha)$ the kinetics dependent model function. The Arrhenius equation generally expresses the explicit temperature dependency of the rate constant (Equation 3) 


$$
\frac{d \alpha}{d t}=A \exp \left(\frac{-E_{a}}{R T}\right) f(\alpha)
$$

The A, E and $f(\alpha)$ are called the kinetic triplet that can characterise a unique decomposition reaction. Under non-isothermal conditions in which a sample is heated at a constant rate, the explicit time dependence in Equation 2 is eliminated through the trivial transformation (Equation 4)

$$
\frac{d \alpha}{d t}=\frac{A}{\beta}\left(\frac{-E_{a}}{R T}\right) f(\alpha)
$$

where $\beta=\mathrm{dT} / \mathrm{dt}$ is the heating rate. Upon integration, Equation 2 gives Equations 5, 6 and 7

$$
\begin{aligned}
& g(\alpha)=\int_{0}^{\alpha} \frac{d \alpha}{f(\alpha)}=\frac{A}{\beta} \int_{0}^{T} \exp \left(\frac{-E a}{R T}\right) f(\alpha) \\
& \approx \frac{A}{\beta} \int_{0}^{T} \exp \left(\frac{-E_{a}}{R T}\right) d T=\frac{A E_{a}}{R \beta} \int_{0}^{x_{\alpha}} \exp \left(\frac{-x}{x^{2}}\right) d x \\
& =\frac{A E_{a}}{R \beta} p(x) \equiv \frac{A}{\beta} I\left(E_{a}, T\right)
\end{aligned}
$$

where $\mathrm{P}(\mathrm{x})$ is the exponential integral for $\mathrm{x}=\mathrm{E}_{\mathrm{a}} / \mathrm{RT}$. The temperature integral $\mathrm{I}(\mathrm{E} \alpha, \mathrm{T})$ has no analytical solution but many approximations.

The linear iso conversional integral method has been suggested independently by Flynn and Wall and Ozawa use Dolyle's approximation of $\mathrm{P}(\mathrm{x})^{[8]}$. This method is based on the Equation 8

$$
\ln \beta=\ln \left(\frac{A E_{0}}{R g(\alpha)}\right)-5.3305-1.052\left(\frac{E_{a}}{R T}\right)
$$

Thus for $\alpha=$ const. The plot $\ln \beta$ versus (1/T) obtained from thermograms recorded at several heating rates should be a straight line, the slope of which can be used to evaluate the apparent activation energy $\mathrm{E}_{\alpha}$.

A nonlinear iso-conversional method has been developed by Vyazovekin that avoids inaccuracies associated with analytical approximation of the temperature integral ${ }^{7}$, for a set of $\mathrm{n}$ experiments carried out at a different heating rates, the activation energy can be determined at any particular value of $\alpha$ by finding the value of $\mathrm{E}_{\mathrm{a}}$ for which this objective function $\Omega$ is minimised, where (Equations 9 and 10)

$$
\begin{aligned}
& \Omega=\sum_{i-1}^{n} \sum_{j \neq i}^{n} \frac{I\left(E_{a, \alpha}, T_{a, i}\right) \beta_{j}}{I\left(E_{a, \alpha}, T_{a, j}\right) \beta_{i}} \\
& \text { and } \\
& I\left(E_{a, \alpha}, T_{\alpha, i}\right)=\int_{o}^{t_{\alpha, i}} \exp \left(-\frac{E_{a, \alpha}}{R T}\right) d T
\end{aligned}
$$

We have developed a mathematical program to evaluate the temperature integral and the result have been compared with Cai et al. ${ }^{8}$ approximation where (Equation 11)

$$
\int_{\mathrm{o}}^{\mathrm{T}} \exp \left(-\frac{E_{a, \alpha}}{R T_{\alpha, i}}\right) d T=\frac{R T_{a, \alpha, i}^{2}}{E_{a, \alpha}}\left[\frac{\frac{E_{a, \alpha}}{R T_{\alpha, i}}+0.66691}{\frac{E_{a, \alpha}}{R T_{\alpha, i}}+2.64943}\right] \exp \left(\frac{-E_{a, \alpha}}{R T_{\alpha, i}}\right)
$$

\section{Results and Discussion}

Figure 1 shows typical TG/DTA curves for un-irradiated $\operatorname{In}(\mathrm{acac})_{3}$ in static air. The TG curve showed that the decomposition of $\operatorname{In}(\mathrm{acac})_{3}$ proceed in one major step in the temperature range of $150-250{ }^{\circ} \mathrm{C}$ with the formation of $\mathrm{In}_{2} \mathrm{O}_{3}$ as a solid residue according to the following Equation 12.

$$
2 \mathrm{In}(\mathrm{acac})_{3} \rightarrow \mathrm{In}_{2} \mathrm{O}_{3}+\text { volatiles }
$$

The acetylacetonate ligand was found as the major gaseous product below $300{ }^{\circ} \mathrm{C}$. At a temperature higher than $400{ }^{\circ} \mathrm{C}$ the ligand decomposed mainly to $\mathrm{CO}, \mathrm{CO}_{2}$, and $\mathrm{H}_{2} \mathrm{O}$. The main decomposition step in the TG curve of In(acac) ${ }_{3}$ was accompanied by an endothermic peak at $\approx 180{ }^{\circ} \mathrm{C}$. The $\mathrm{TG}$ curve showed a weight gain in the temperature range of $300-350{ }^{\circ} \mathrm{C}$ accompanied by two overlapped exothermic peaks due to the formation of $\operatorname{In}_{2} \mathrm{O}_{3}$ followed by the crystallization of the oxide product. Another weight gain was detected in the TG curve of $\mathrm{In}(\mathrm{acac})_{3}$ in the temperature range of $900-1000{ }^{\circ} \mathrm{C}$ and could be attributed to the formation of more non stoichiometric complex oxides. Similar observation has been made for several metal acetylacetonates earlier ${ }^{9}$. TG/DTA curves of $\gamma$-irradiated $\operatorname{In}(\mathrm{acac})_{3}$ with $10^{2} \mathrm{KGy}$ total $\gamma$-ray dose show almost the same decomposition behaviour as for un-irradiated ones, except that the temperature range of the decomposition was shifted to lower value $\left(130-230^{\circ} \mathrm{C}\right)$ in case of $\gamma$-irradiated sample. TG/DTA curves for $\gamma$-irradiated In(acac) $)_{3}$ with $10^{2} \mathrm{kGy}$ total $\gamma$ ray dose showed almost the same behaviour for the decomposition of un-irradiated sample. The dynamic data for both un-irradiated and $\gamma$-irradiated $\operatorname{In}(\mathrm{acac})_{3}$ with $10^{2} \mathrm{kGy}$ total $\gamma$-ray dose are shown in Figure 2. The application of both linear (FWZ) and non-linear (VYZ) model free isoconversional methods, to the non isothermal decomposition data for both unirradiated and $\gamma$-irradiated $\operatorname{In}(\mathrm{acac})_{3}$ with $10^{2} \mathrm{kGy}$ total $\gamma$ ray dose permits a determination of $\mathrm{E}_{\alpha}$ as a function of $\alpha$ and results are shown in Figure 3. The results of the application of these two model free on the investigated data in general showed a symmetric dependence of $\mathrm{E}_{\mathrm{a}}$ on $\alpha$ indicating a simple decomposition process with almost the same estimated values of $\mathrm{E}_{\text {a }}$ using both linear (FWO) and non-linear (VYZ) methods. $\mathrm{E}_{\mathrm{a}}$ is $\approx 140 \mathrm{kJmol}^{-1}$ and $120 \mathrm{kJmol}^{-1}$ at the start of decomposition, then reach a minimum of a $80 \mathrm{kJmol}^{-1}$ at the end of the decomposition for both un-irradiated and $\gamma$-irradiated samples. The relative lower $\mathrm{E}_{\mathrm{a}}$ value obtained at the start of decomposition for $\gamma$-irradiated sample could be attributed to the formation of additional decomposition centres created by trapped electrons and holes in the host lattice.

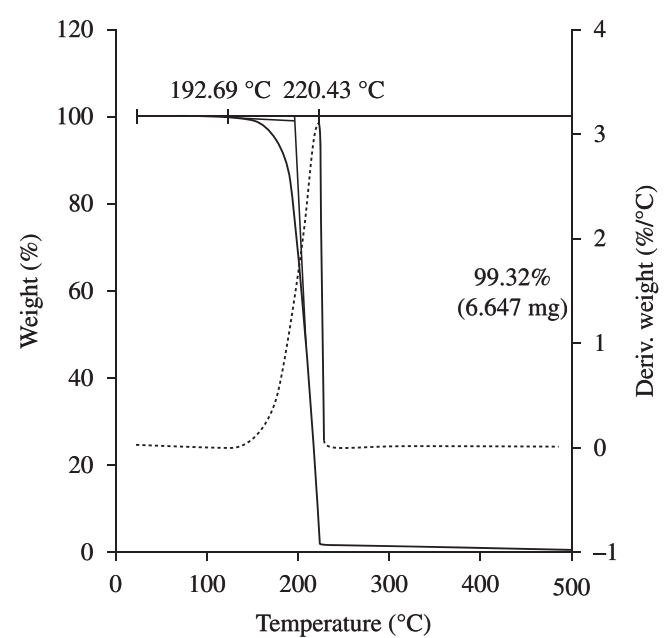

Figure 1. Simultaneous TG and DTA curves of $\gamma$-irradiated $\operatorname{In}(\mathrm{acac})_{3}$. 

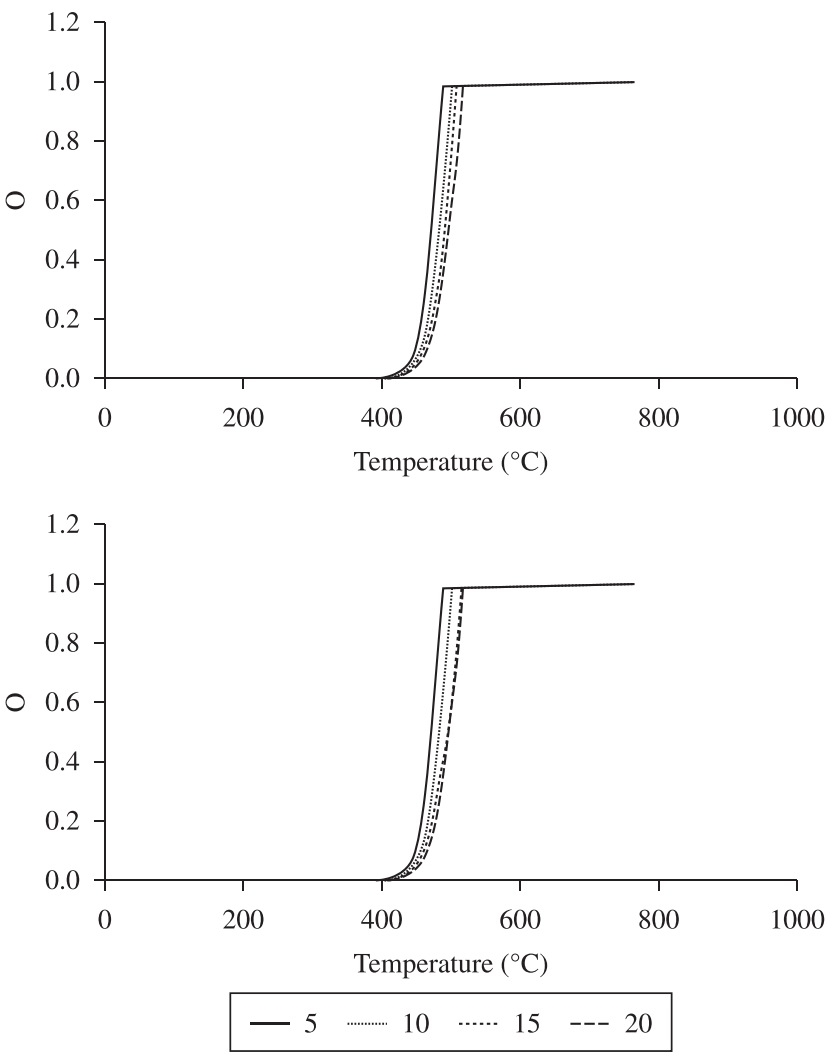

Figure 2. Thermogravimetric data showing the extent of unirradiated $\operatorname{In}(\mathrm{acac})_{3}$ conversion during nonisothermal decomposition. The heating rate of each experiment (in ${ }^{\circ} \mathrm{C} / \mathrm{min}$ ) is indicated by each curve.
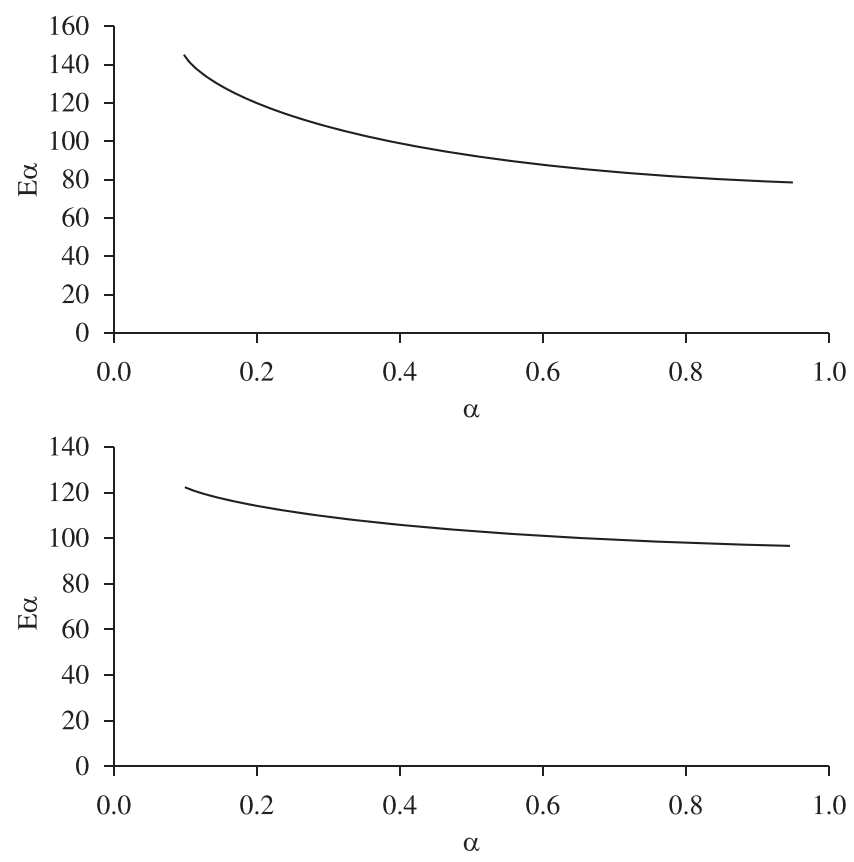

Figure 3. Dependence of activation energy on extent of conversion determined using iso conversional method. Top: un-irradiated and bottom: $\gamma$-irradiated $\left(10^{2} \mathrm{KGy}\right)$ In $(\mathrm{acac})_{3}$.

\subsection{IR, XRD and SEM measurements}

Figure 4 show IR spectra of both un-irradiated and $\gamma$ irradiated $\operatorname{In}(\mathrm{acac})_{3}$. Both spectra display the characteristic bands assigned to various vibration modes of acetylacetonate functional groups. Neither disappearance nor appearance of new bands was recorded in the IR spectrum of $\gamma$-irradiated $\operatorname{In}(\mathrm{acac})_{3}$ with $10^{2} \mathrm{kGy}$ total $\gamma$ ray dose, but a decrease in the intensity of most characteristic bands was recorded as a results of $\gamma$-irradiation. The band assigned to $v$ In-O bond around $660 \mathrm{~cm}^{-1}$ was more affected by irradiation than any other band in the spectrum. The decreased in the intensity of this band could be attributed to bond scission and degradation caused by $\gamma$ irradiation. IR bands for In(acac), and their assignments are listed in Table 1 .

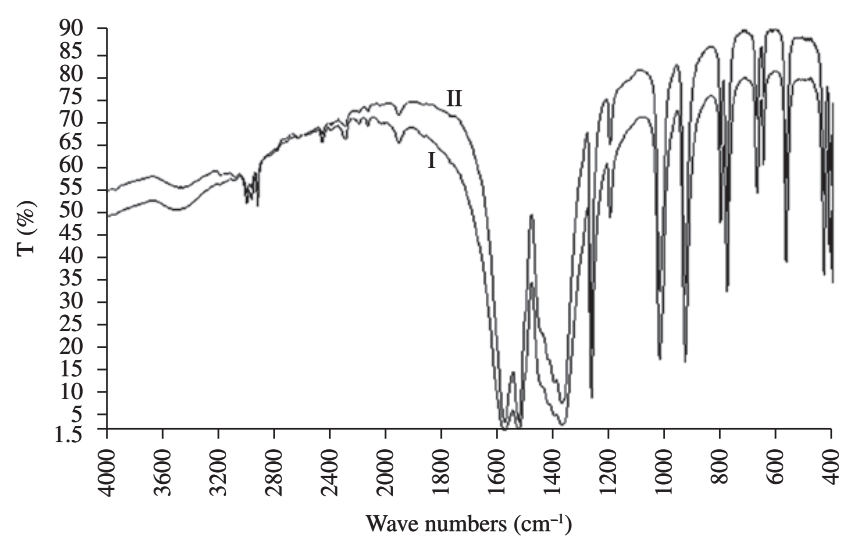

Figure 4. IR spectra of I) unirradiated In(acac $)_{3}$; and II) $\gamma$ irradiated $\operatorname{In}(\text { acac })_{3}$.

Table 1. IR bands of In(acac) ${ }_{3}$ and their assignments:

\begin{tabular}{|c|c|c|}
\hline \multicolumn{2}{|c|}{ Band position } & \multirow[b]{2}{*}{ Assignment } \\
\hline $\begin{array}{c}\operatorname{In}(\text { acac })_{3} \\
\gamma \text {-irradiated } \\
\left(10^{2} \mathrm{kGy}\right)\end{array}$ & $\begin{array}{c}\operatorname{In}(\mathrm{acac})_{3} \\
\text { un-irradiated }\end{array}$ & \\
\hline 2920.81 & 2929.66 & $v(\mathrm{CH}) \quad v\left(\mathrm{CH}_{3}\right)$ \\
\hline 1518.33 & 1518.33 & $V(C=-C)+V(C=C)$ \\
\hline 1425.92 & 1424.60 & $\delta_{\mathrm{d}}\left(\mathrm{CH}_{3}\right)$ \\
\hline 1377.81 & 1364.73 & $\delta_{\mathrm{s}}\left(\mathrm{CH}_{3}\right)$ \\
\hline 1296.75 & 1296.49 & $\mathrm{~V}\left(\mathrm{C}-\mathrm{CH}_{3}\right)+\mathrm{V}(\mathrm{C}---\mathrm{C})$ \\
\hline 1019.91 & 1018.98 & $\rho_{\mathrm{r}}\left(\mathrm{CH}_{3}\right)$ \\
\hline 935.83 & 935.38 & $V(C=-C)+V(C=-O)$ \\
\hline 781.41 & 780.97 & $\pi(\mathrm{CH})$ \\
\hline 688.38 & 683.52 & $v\left(\mathrm{C}-\mathrm{CH}_{3}\right)+$ ring def. \\
\hline 664.19 & 660.17 & $v \operatorname{In}_{2} \mathrm{O}_{3}$ \\
\hline 640.68 & 640.46 & $\pi\left(\mathrm{CH}_{3}-\mathrm{C}^{\prime}{ }_{\mathrm{O}}\right)$ \\
\hline 455.02 & 455.01 & $v\left(\mathrm{C}-\mathrm{CH}_{3}\right)+v \mathrm{In}_{2} \mathrm{O}_{3}$ \\
\hline
\end{tabular}




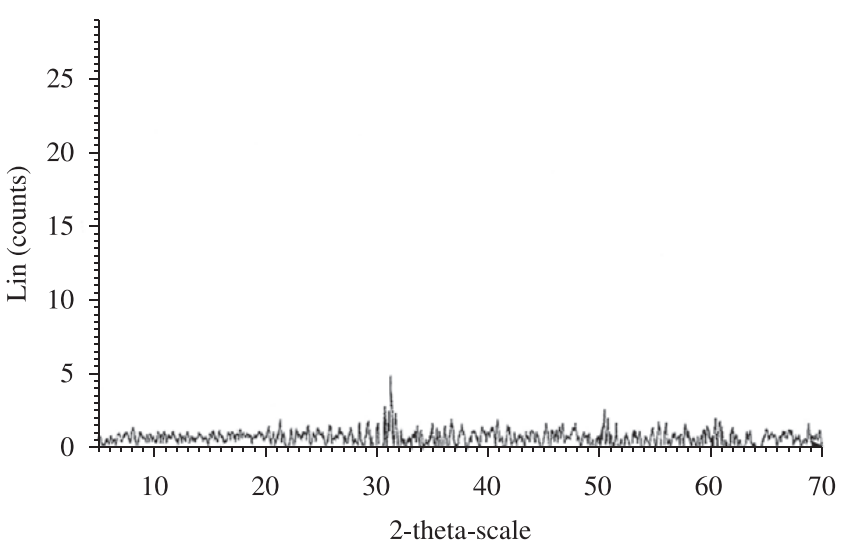

Figure 5. XRD pattern of $\operatorname{In}_{2} \mathrm{O}_{3}$ nanoparticles.

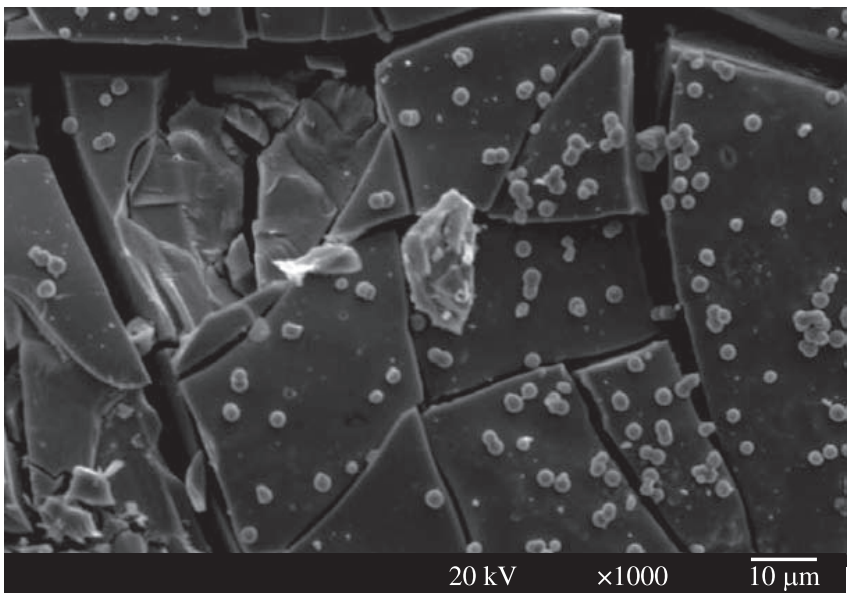

Figure 6. SEM showing the formation of circular nanoparticles of $\operatorname{In}_{2} \mathrm{O}_{3}$.

XRD patterns of un-irradiated and $\gamma$-irradiated $\operatorname{In}(\text { acac })_{3}$ both showed the same characteristic features of monoclinic system without any significant changes occurred as a results of $\gamma$-irradiation with $10^{2} \mathrm{kGy}$ total $\gamma$-ray dose. XRD and IR measurements were employed to follow the formation of $\operatorname{In}_{2} \mathrm{O}_{3}$ nanoparticles by calcination of both un-irradiated and G-irradiated $\mathrm{In}(\mathrm{acac})_{3}$ at different temperatures and different time intervals. From these experiments we concluded that the calcination of $\operatorname{In}(\mathrm{acac})_{3}$ at $400{ }^{\circ} \mathrm{C}$ for four hours led to the formation of $\operatorname{In}_{2} \mathrm{O}_{3}$ nanoparticles as was demonstrated by XRD and SEM shown in Figures 5 and 6 respectively. The average particle size calculated from both SEM measurements and Debye-Scherrer equation appear to be less than $1 \mu \mathrm{m}$.

It should be mentioned that the formation of the solid residue initially started by formation of indium(0) metal. The In metal oxidised to $\mathrm{In}_{2} \mathrm{O}_{3}$ with the increase of heating temperature as well as with prolonged heating time at the same temperature. This conclusion is further supported by the TG results.

\section{Acknowledgements}

This work was supported by the College of Science, Research Center, King Saud University grant number Chem/2008/33

\section{References}

1. Mahfouz RM, Siddiqui MRH, Al-Ahmari ShA and Alkayali WZ. Kinetic analysis of thermal decomposition of unirradiated and $\gamma$-irradiated tris acetylacetonate ruthenium (III) $\left[\mathrm{Ru}(\mathrm{acac})_{3}\right]$. Progress in Reaction Kinetics and Mechanisim. 2007; 32:1.

2. Mahfouz RM, AL-Ahmari SHA, Warad IKH, AL-Resayes SI, Siddiqui MRH, Raslan KR et al. Kinetics of the Non-isothermal decomposition of un-irradiated and $\gamma$-irradiated ruthenium(III) acetylacetonate $\left[\mathrm{Ru}(\mathrm{acac})_{3}\right]$. Radiation Effects \& Defects in Solids. in press.

3. Brown WE, Dollimore D and Galwey AK. Comprehensive Chemical Kinetic. Amsterdam: Elsevier; 1980. v. 22.

4. Mahfouz RM, Alshehri SM, Monshi MAS and Abd El-salam NM. Isothermal decomposition of $\gamma$-irradiated samarium acetate. Radiation Physics and Chemistry. 2000; 59:381.

5. Steffes H, Jmawan C, Sozbacher F and Obermeier E. Enhancement of $\mathrm{NO}_{2}$ sensing properties of $\operatorname{In}_{2} \mathrm{O}_{3}$-based thin films using an $\mathrm{Au}$ or Ti surface modification. Sensors and Actuators. 2001; 78:106.

6. Tanaka S and Esaka T. Characterization of NOx sensor using doped $\operatorname{In}_{2} \mathrm{O}_{3}$. Journal of Materials Research. 2001; 16:1389.

7. Vyazovkin S. Computational aspects of kinetic analysis. Part C. The ICTAC Kinetics Project - The light at the end of the tunnel? Thermochimica Acta. 2000; 355:155.

8. Cai J, Yao F, Yietal W and AIch E. New temperature integral approximation for nonisothermal kinetics. AIChE Journal. 2006; 52:1554.

9. Siddiqui MA, Siddiqui RA and Atakan B. Thermal stability sublimation pressures and diffusion coefiicients of some metal acetylacetonates. Surface and Coatings Technology. 2007; 201:9055. 